\title{
Temporalidade e cronotopo na minissérie televisiva Se eu fechar os olhos agora
}

\section{Temporality and chronotope in the TV miniseries Se eu fechar meus olhos agora (If I close my eyes now)}

Maria Cristina Palma Mungioli ${ }^{1}$ 


\section{Resumo}

O presente artigo discute elementos da poética das séries de televisão (Mittell, 2015) a partir da construção discursiva de sua temporalidade. Após discussão baseada em aspectos da narratologia (RICOEUR, 1983; ECO, 1997; BARONI, 2016; GENETTE, 2017), dos estudos de linguagem televisiva (Mittell (2015; JOST (2016) e dos estudos de linguagem de Bakhtin (2010), analisamos aspectos da construção da temporalidade no primeiro capítulo da minissérie. Destacamos o uso de flashbacks e flashforwards como procedimentos narrativos e estilísticos que caracterizam uma arquitetura de puzzle na qual personagens e motivações se configuram e se reconfiguram ao longo da trama por meio da construção da temporalidade. A análise dos cronotopos mostra trama, personagens e conflitos em situações que desnudam os embates sociais e tensionam visões de mundo e conflitos inerentes à vida social em sua perspectiva de construção histórica.

Palavras-chave

Poética de séries de televisão, discurso e temporalidade, cronotopo, minissérie.

\section{Abstract}

This article discusses elements of the poetics of television series (Mittell, 2015) based on the discursive construction of its temporality. After discussion based on aspects of narratology (RICOEUR, 1983; ECO, 1997; BARONI, 2016; GENETTE, 2017), the television language studies (MITTELL, 2015; JOST, 2016), and Bakhtin's language studies (2010), we analyzed aspects of the construction of temporality in the first chapter of the miniseries. We highlight the use of flashbacks and flashforwards as narrative and stylistic procedures that characterize a puzzle architecture in which characters and motivations are configured and reconfigured throughout the plot through the construction of temporality. The analysis of chronotopes shows plot, characters and conflicts in situations that expose social clashes and tension worldviews and conflicts inherent to social life in its perspective of historical construction.

\section{Keywords}

Poetics of television series, speech and temporality, chronotope, TV minisseries. 
Ao longo do presente artigo, pretendemos analisar aspectos da construção discursiva da temporalidade na minissérie Se eu fechar os olhos agora (Estúdios Globo, 2018, 10 capítulos) como parte integrante de uma poética da minissérie que articula a construção de personagens e a própria constituição do enredo². Situamos nossa discussão no contexto atual da chamada cultura de séries (SILVA, 2014) considerada como um fenômeno cultural não apenas relacionado à apropriação de ferramentas tecnológicas por parte dos telespectadores e fãs que ampliariam as práticas e dinâmicas de espectatorialidade (CASTELLANO; MEIMARIDIS, 2016; SACCOMORI, 2016; COMBES, 2015), mas também como tributário de propriedades intrínsecas ao gênero e ao formato serial televisivo (MUNGIOLI, 2019).

Nesse sentido, consideramos como balizadores para a discussão aspectos referentes aos gêneros e formatos seriados entendidos como formas culturais (WILLIAMS, 2016) e mediações culturais (MARTÍN-BARBERO, 2001). Com base nessa perspectiva, entendemos o formato televisivo não apenas como resultante de estratégias comerciais da indústria televisiva, mas também como uma construção estético-cultural. Martín-Barbero (2001) destaca a relevância de se analisarem os gêneros e formatos nos produtos massivos como mediações por meio das quais se articulam as lógicas dos sistemas produtivo e de consumo e suas camadas culturais. Em termos mais específicos, consideramos as séries e minisséries televisivas como formas narrativas (MITTELL, 2006, 2015; JOST, 2011; SEPULCHRE, 2011; MUNGIOLI; PELEGRINI, 2013; SILVA, 2014, 2015; ESQUENAZI, 2014) construídas sobre o eixo da serialidade e "que se inscrevem (...) na linha da cultura popular apropriando-se do legado dos grandes contadores de histórias, escritores de romances e cineastas (...)." (ESQUENAZI, 2014, p. 161)3.

Em uma perspectiva mais diretamente relacionada ao estudo da temporalidade nas séries de televisão na atualidade, Ames (2012, p. 8-9) destaca streaming Net Now em 29 de agosto de 2018. Posteriormente, foi exibida na TV Globo, no horário das 23 horas, de 15 a 30 de abril de 2019 também com 10 capítulos. 
que o formato, a partir dos anos 2000, tem trabalhado a temporalidade de forma bastante diferente da que era feita anteriormente, pois utiliza processos "de retardamento e compressão do tempo" de modo a "perturbar o próprio fluxo cronológico" por meio do "uso extensivo de flashbacks e da insistência para que os espectadores estejam aptos a se localizar eles próprios no presente e no passado simultaneamente". Embora os procedimentos de construção temporal da história por meio do jogo entre passado, presente e futuro diegéticos não sejam uma novidade nas produções televisivas do século XXI, a autora enfatiza em sua argumentação "que nunca antes o tempo narrativo jogou um papel tão importante no mainstream televisivo." (AMES, 2012, p. 9).

Em termos de desenvolvimento do presente texto, situamos a discussão em torno de uma poética das séries de televisão (MITTELL, 2015) considerando a construção discursiva de sua temporalidade. Após discussão baseada em aspectos da narratologia (RICOEUR, 1983; ECO, 1997; BARONI, 2016; GENETTE, 2017), dos estudos de linguagem televisiva (MITTELL, 2015; JOST, 2016) e dos estudos de linguagem de Bakhtin (2010), será realizada a análise de alguns pontos relativos à construção da temporalidade no primeiro episódio da minissérie Se eu fechar os olhos agora. Resumidamente, a minissérie foi lançada pelo serviço SVOD (Subscription Video on Demand) Net Now, em 29 de agosto de 2018. Posteriormente, foi exibida na TV Globo, entre 15 e 30 abril de 2019, no horário das 23 horas. Indicada ao prêmio Emmy Internacional de 2019 na categoria de melhor minissérie, a produção encontra-se atualmente no catálogo do serviço por assinatura Globoplay.

\section{Construção discursiva da temporalidade: elementos para discussão e análise}

A discussão proposta neste artigo considera a temporalidade e a sua construção discursiva em um produto ficcional televisivo como elementos constituintes de uma poética de séries televisivas. Como se sabe, tais elementos se interrelacionam intrínseca e complexamente tanto em termos estruturais quanto em termos de produção de sentidos na composição da trama narrativa. No entanto, devido às limitações e objetivos do presente trabalho, não realizaremos 
um mapeamento exaustivo das diversas concepções em torno da temporalidade narrativa. Traremos algumas contribuições provenientes dos estudos audiovisuais, dos estudos de narratologia e dos estudos de linguagem efetuados por Bakhtin (1993; 2003) com o objetivo de colher subsídios teóricos e ferramentas de análise que se relacionem mais diretamente com a nossa proposta de estudo.

Genette (2017, p. 89), ao apresentar seu estudo em torno dos tempos da narrativa, tendo como objeto "as relações temporais entre narrativa e diegese", ou "a ordem", apresenta como epígrafe a clássica definição de Metz (2010, p. 31) acerca da construção temporal da narrativa: "Um início, um final: quer dizer que a narração é uma sequência temporal. Sequência duas vezes temporal, devemos acrescentar logo: há o tempo do narrado e o da narração (tempo do significado e tempo do significante)". Genette (2017, p. 91, grifos do autor) destaca que não apenas a narrativa cinematográfica, mas também a oral, apresenta a dualidade apontada por Metz, ou seja, a diferenciação entre tempo da história (erzäh/te Zeit) e tempo da narrativa (Erzählzeit); respectivamente, o tempo que decorre no interior da história e o tempo que se leva para ler a história. Para Genette (2017, p. 92), no caso do filme, em princípio, é possível modificar a ordem de leitura alterando-se a sucessividade dos fatos narrados.

No entanto, o texto escrito possui uma construção mais "amarrada" devido à própria "linearidade do significante linguístico". De acordo com Genette (2017, p. 93), "estudar a ordem temporal de uma narrativa é confrontar a ordem da disposição dos acontecimentos ou segmentos temporais no discurso narrativo com a ordem de sucessão desses mesmos acontecimentos ou segmentos temporais na história (...)." Ainda na linha dos estudos da narrativa, Ryan (2010, p. 20) afirma "como os narratologistas observaram há bastante tempo, as narrativas obedecem a uma dupla ordem temporal: a ordem dos acontecimentos no mundo narrativo e a ordem segundo a qual esses acontecimentos são apresentados ao público".

O aspecto referente à composição e à organização da narrativa e sua correlação com as formas de temporalidade foi estudado pelos chamados formalistas russos e pode ser pode ser observado na clássica definição de Tomachevski 
([1925] 1976, p. 173), segundo a qual "a fábula é o que se passou; a trama é como o leitor toma conhecimento dele". Desenvolvendo essa definição, Eco (1986, p. 85) afirma que "fábula é o esquema fundamental da narração, a lógica das ações e a sintaxe das personagens, o curso dos eventos ordenado temporalmente." E acrescenta, "o enredo pelo contrário, é a história como de fato é contada (...), com as deslocações temporais, saltos para frente e para trás (ou seja, antecipações e flash-back)". Tal definição se assemelha à de Forster ([1927] 1998) segundo a qual história e enredo não são a mesma coisa. Para Forster (1998, p. 83), a história "é uma narrativa de acontecimentos dispostos em sequência no tempo. Um enredo é também uma narrativa de acontecimentos, cuja ênfase recai sobre a causalidade". Forster (1998, p. 84) adverte que, na composição de um enredo, não basta criar ganchos que prendam a atenção do leitor apenas pela curiosidade, mas um bom enredo "também exige inteligência e memória".

De uma forma bastante resumida, podemos dizer que a construção da temporalidade nas narrativas não está apenas relacionada a procedimentos mais comumente observados na superfície da narrativa e que dizem respeito mais diretamente às anacronias, ou seja, às "diferentes formas de discordância entre a ordem da história e a da narrativa" (GENETTE, 2017, p. 89) como elipses, analepses (flashbacks) e prolepses (flashforwards), mas está implicada na própria constituição da trama sobre a qual se constrói a intriga. Enfatizando essa questão, Ricoeur afirma que:

\footnotetext{
Seguir uma história é avançar entre contingências e peripécias sob a condução de uma expectativa que encontra sua realização na conclusão. (...) Compreender a história é compreender como e por que os episódios levaram a tal conclusão, que, longe de ser previsível, deve ser aceitável, de forma congruente com os episódios como um todo (RICOEUR, 1983, p. 130).
}

A complexidade da construção da temporalidade também pode ser observada na própria composição da narrativa que envolve, segundo Baroni (2016, p. 1), além dos aspectos formais, emoções como medo e esperança. Tais emoções também devem consideradas para a análise das três partes que compõem a história (início, meio e fim): 
já que as ações dadas se desenrolam no tempo, o medo e a esperança [emoções] orientam a atenção do público para uma resolução incerta, e a unidade da representação é assegurada pela função catafórica [organizadora na forma de pensar como coesão] do início e pela função anafórica [repetição, reiteração do motivo desencadeador mostrado no início] do fim (BARONI, 2016, p. 1).

Por sua vez, Gaudreault e Jost (2017, p. 159) advertem que os conceitos propostos por Genette dizem respeito ao campo da narratologia literária, enfocando em princípio o romance, obra realizada em um meio homogêneo em termos de matéria de expressão: o texto escrito. Para os autores, "se quisermos estar em condições de analisar toda a teia temporal [da narrativa] audiovisual, é preciso considerarmos sucessivamente o tempo romanesco e o tempo cinematográfico" (GAUDREAULT; JOST, 2017, p. 159). Dessa forma, constituem objetos de análise, a enunciação de personagens e narradores, o discurso verbal e a linguagem fílmica propriamente dita. Como frisam os autores, o filme encerra uma "dupla narrativa, pois a ordem temporal produz frequentemente um resultado complexo que mescla o que é apresentado visualmente pelos atores e aquilo que é contado verbalmente por um narrador" (GAUDREAULT; JOST, 2017, p. 164).

Dessa forma, a construção discursiva da temporalidade não se caracteriza apenas por uma mecânica que envolve flashbacks ou flashforwards, mas embasa a construção da intensidade e densidade dramáticas que atuam cumulativamente na construção da trama e das personagens. Adicionam-se intensidade e densidade por meio, principalmente, de flashbacks que remetem a motivos e significados que se associam ao evento do presente diegético e é nesse presente que a narrativa se complexifica, envolvendo enunciados fílmicos e verbais que exigem do espectador não apenas o acompanhamento dos acontecimentos para entendimento do mundo ficcional, mas também os sentidos produzidos pelos enunciados verbais, modalizando as diferentes instâncias de enunciação (fílmica, verbal e sua organização discursiva na ordem temporal). 
Em perspectiva mais diretamente relacionada a uma poética das séries de televisão, Mittel $(2006 ; 2015)$ considera a construção da temporalidade como um dos fatores mais salientes daquilo que ele denomina complexidade narrativa. Para o autor, a trama ganha complexidade por meio do uso da temporalidade não apenas como um elemento que situa um evento cronologicamente dentro da história, mas também como uma forma de acrescentar camadas de significação aos eventos e aprofundar nosso conhecimento acerca das personagens e do mundo ficcional.

Resumidamente, considerando o tempo da narrativa, Eco (1997) e Mittell (2015) afirmam que, de maneira geral, em toda história há: "(1) tempo da história (da narrativa): o tempo que decorre no interior da narrativa; (2) tempo do discurso: construído pelo discurso, e pode conter elipses, flashforwards, flashbacks; (3) tempo da narração: o tempo para contar a história (na televisão e no cinema: screen time)" (MUNGIOLI, 2019, p. 163). É em relação à segunda definição, referente ao tempo do discurso, que procederemos à análise, pois pretendemos observar como flashbacks e flashforwards atuam na composição do jogo incessante entre passado e presente diegéticos por meio de uma organização discursiva. No presente artigo, será objeto de nossas discussões a construção da temporalidade por meio do discurso.

Tratando da temporalidade e de sua construção estética no texto literário, Bakhtin (2010) propõe uma outra chave de interpretação que se baseia na relação indissolúvel entre tempo e espaço - o cronotopo:

No cronotopo artístico-literário ocorre a fusão dos indícios espaciais e temporais num todo compreensivo e concreto. Aqui o tempo condensa-se, comprime-se, torna-se artisticamente visível; o próprio espaço intensificase, penetra no movimento do tempo, do enredo e da história. Os índices do tempo transparecem no espaço, e o espaço reveste-se de sentido e é medido com o tempo. Esse cruzamento de séries e a fusão de sinais caracterizam o cronotopo artístico (BAKHTIN, 2010, p. 211).

Nessa perspectiva, a construção da temporalidade está vinculada inexoravelmente ao espaço, entendido como espaço da vida social, e só faz sentido quando compreendido a partir dessa relação: 
A relação tempo-espaço é dinâmica e organicamente construída de maneira concomitante pelo autor, obra e leitor na medida em que todos se inserem no quadro da comunicação dialógica. O cronotopo assimilado na manifestação conteudístico-formal da obra (literária) encerra em si uma imagem do herói, uma espécie de visão de mundo (Weltanschauung) e é compreendida como tal pelo leitor. Assim, na literatura, a característica cronotópica emergiria da maneira como as pessoas são representadas e, por conseguinte, se concretizaria por meio das expansões/contrações das dimensões espaciais e temporais nas quais atuariam essas pessoas. Assim, o cronotopo da vida cotidiana é caracterizado pelas relações sociais, enquanto o cronotopo de aventuras é caracterizado pelas sucessões operadas no espaço físico (MUNGIOLI, 2013, p. 107).

Cabe enfatizar, portanto, que, na perspectiva da comunicação dialógica que rege as análises de Bakhtin (2003; 2010), o leitor (em nosso caso, o telespectador) assume papel preponderante na própria configuração do cronotopo. Todorov (1981, p. 129) afirma que a noção de cronotopo "não [se] relaciona simplesmente à organização do tempo e do espaço, mas também à organização do mundo (que pode legitimamente se chamar cronotopo na medida em que o tempo e o espaço são as categorias fundamentais de todo universo imaginável)" (TODOROV, 1981, p. 129, grifo do autor).

As relações entre tempo e espaço na obra artística constituem-se, para Bakhtin, por meio do acabamento estético que permite a apreensão do momento histórico e das eventuais mudanças por meio da maneira com que as pessoas são representadas nas produções, conforme salientam Clark e Holquist (1998, p. 296-300). A perspectiva de análise por meio do conceito de cronotopo insere trama, personagens e conflitos em situações (do cotidiano) que desnudam os embates sociais e tensionam visões de mundo e conflitos inerentes à vida social em sua perspectiva de construção histórica. Dessa forma, o "universo imaginável" (TODOROV, 1981, p. 129) torna-se apreensível com base em um jogo constante entre a criação estética, apreensível por meio do cronotopo criado, e suas relações com determinado momento histórico e social no qual trama, personagens e leitores (telespectadores, em nosso caso) estão dialogicamente imersos.

Para Bakhtin (2003, p. 246), o romance "deve apresentar um quadro integral do mundo e da vida, deve refletir o mundo todo e a vida toda. No romance, 
o mundo todo e a vida toda são representados em um corte da totalidade da época. Os acontecimentos representados devem abranger de certo modo toda a vida de uma época" (grifos do autor). Embora o cronotopo artístico seja apreensível como tal a partir da do acabamento temático e estético, cabe enfatizar que não se trata de um mundo à parte do mundo representado. Ao contrário, trata-se de um mundo representado que se constrói dialogicamente e que, por isso, guarda relações dinâmicas e orgânicas com o mundo que se representa. São zonas fronteiriças. Clark e Holquist (1998, p. 297) afirmam que "o cronotopo é uma ponte, não um muro, entre dois mundos". O entrelaçamento e o diálogo entre esses dois mundos (o mundo ficcional e a realidade) é realizado pelo dialogicamente pelo autor, ouvinte, leitor (telespectador) da história.

\section{Aspectos da construção da temporalidade e cronotopos na minissérie Se eu fechar os olhos agora}

Devido aos limites do presente artigo, trataremos mais incisivamente da construção temporal do primeiro capítulo da minissérie, já que é nele que "todos os personagens principais do conjunto devem ser apresentados" (PALLOTTINI, 1998, p. 80). Além disso, é no primeiro capítulo que, em geral, conhecemos os conflitos básicos frente aos quais as personagens deverão agir. Ou seja, expõe as personagens em ação no mundo, mostra-nos suas motivações, seus conflitos e indica-nos, de maneira mais clara ou mais nebulosa, os possíveis desdobramentos que esses conflitos poderão ter ao longo da série.

A minissérie, que pode ser definida como pertencente ao gênero thriller ${ }^{4}$, tem como eixo central a investigação sobre o assassinato de Anita (Thainá Duarte), cercado de mistério na cidade fictícia de São Miguel no interior do estado do Rio de Janeiro em abril de 1961. O cadáver da bela jovem de origem humilde e casada com Francisco (Renato Borghi), o dentista da cidade, é encontrado por 
dois adolescentes, Paulo Roberto (João Carlos D'Aleluia) e Eduardo (Xande Valois) à beira de um lago distante do centro da cidade. Inicialmente, considerados suspeitos do crime, os dois garotos são presos e soltos após o dentista confessar a autoria do assassinato. Pouco tempo após a confissão, Francisco é encontrado morto em sua cela na cadeia da cidade. A polícia local afirma que o dentista se suicidou. Após a morte de um jornalista - um conhecido do menino Paulo Roberto -, que desconfiava da história do suicídio de Francisco - e convencidos de que a polícia não quer elucidar os assassinatos, os dois garotos, com a ajuda de Ubiratan (Antonio Fagundes) - um morador do asilo da cidade -, realizam investigações paralelas. As investigações os levam a encontrar pistas de que personalidades importantes da cidade estão envolvidas nesse e em outros crimes. Por fim, os garotos e Ubiratan descobrem quem é o assassino de Anita e elucidam outros crimes correlacionados.

A narrativa da minissérie tem início por meio do recurso de abertura fria ${ }^{5}$, bastante usada em séries de televisão que, de maneira geral, atende às necessidades do fluxo televisivo (WILLIAMS, 2016) e pode servir para prender a atenção do telespectador ao mostrar a situação de instabilidade que irá se constituir como o conflito principal da narrativa. Tais especificidades remetem ao formato seriado televisivo e suas implicações em termos de estrutura de uma forma cultural (WILLIAMS, 2016) e formas de recepção permeadas pelas mediações (e espectatorialidade) (MARTÍN-BARBERO, 2001). A abertura do primeiro capítulo mostra Anita, de camisola, correndo entre árvores e sendo perseguida por um homem acompanhado de um cachorro feroz. Anita cai e em seguida o cachorro é solto para ataca-la e a imagem congela e vemos seu pavor (Figura 1). 


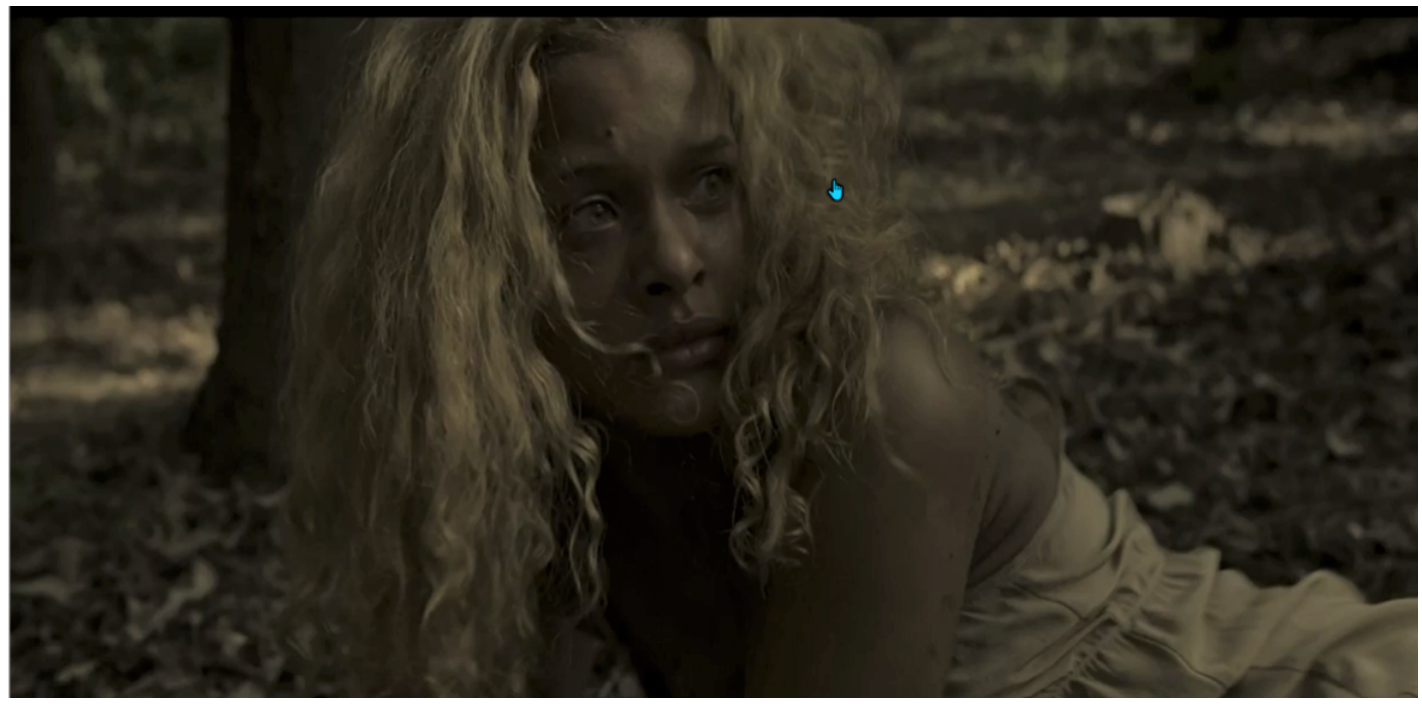

FIGURA 1. Anita caída no chão, encurralada, prestes a ser atacada pelo cachorro.

Fonte: Reprodução Globoplay, captura de tela realizada pela autora do artigo

Essa cena dura cerca de 40 segundos. Entram os créditos iniciais e o título do primeiro episódio é mostrado: "A terra é azul". Na sequência seguinte (de mais ou menos 3 minutos), vemos um homem com uma maleta médica sendo conduzido por outro homem até um quarto onde está Anita ferida e deitada sobre uma cama. O primeiro homem se apresenta a Anita como médico e a examina, e diz que ela não tem apenas os ferimentos das mordidas do cão. O outro homem então diz para o médico se ocupar apenas dos ferimentos da mordida do cão e sai da sala. Anita, que até então estivera calada, tenta se comunicar com o médico. O outro homem percebe isso e volta para quarto e dá um tiro na cabeça do médico. O sangue dele espirra em Anita e ela grita apavorada.

Embora as situações apresentadas nas sequências iniciais não se configurem como as causas diretas do assassinato da jovem, cabe destacar o papel essencial delas para a elaboração de cronotopos - mediados pela criação estética (e acabamento temático) - do "universo imaginável" (TODOROV, 1981, p. 129) que compõe a história. Ganham espaço nessa construção o cronotopo da violência contra a mulher perpetrada por homens em lugares como bosques, florestas e em espaços domésticos privados, sobretudo quartos. Ou seja, cronotopos que se caracterizam por relações entre espaço-tempo que localizam conflitos dessa natureza em espaços "fora da 
visão" da sociedade, ou mais precisamente nos espaços comumente denominados como da vida privada. As situações apresentadas inserem-se concretamente em uma relação tempo/espaço que se densifica e dialoga não apenas com aquilo que vemos na tela, mas também como nosso saber enciclopédico (ECO, 1997).

Cabe ressaltar, no entanto, que embora o elemento de violência contra a mulher, na minissérie analisada, localize-se em um passado recente, as situações de perseguição e violência contra a mulher nos espaços acima citados constituem-se como topoi da literatura e das produções audiovisuais. Dessa forma, os cronotopos construídos pela criação estética e acabamento temático das cenas da minissérie compõem o universo da história, dando-Ihe estrutura e configurando personagens e conflitos, situando-os no interdiscurso. Simultaneamente, tais cronotopos configuram expectativas e emoções (BARONI, 2016) que possibilitarão ao espectador acompanhar o desenvolvimento da trama e desejar saber a continuidade dela.

Após as sequências acima descritas, temos o letreiro "Dois anos depois. São Miguel, RJ". A cidade e seus moradores nos são apresentados ao som da música "Mr. Sandman" (1954) que se contrapõe às cenas de violência que descrevemos acima. Um plano geral mostra a cidade de São Miguel, a igreja da Matriz. A câmera se aproxima e vemos - por meio de uma sequência de primeiros planos intercalados com função de detalhe - carros circulando, pessoas bem arrumadas entrando na igreja e crianças correndo para entrar no colégio. Surge então o garoto Paulo Roberto, indo de bicicleta para a escola (a câmera o acompanha) e vemos crianças em fila entrando nas salas do colégio. A música e o figurino transportam-nos para a atmosfera dos anos 1950. Na sequência, surge Paulo Roberto (Milton Gonçalves) já idoso escrevendo ao computador e nos damos conta de que ele está escrevendo a história que nos será mostrada. Sua voz lê o texto que está na tela do computador e que descreve o que ele sentiu ao encontrar, ainda menino juntamente com Eduardo, o cadáver de Anita. Essa cena nos revela o tempoespaço (presente) do narrador e tomamos conhecimento do foco narrativo de primeira pessoa que acrescenta à história o ingrediente biográfico e testemunhal de que a narrativa se reveste. Dessa forma, colocam-se em marcha mecanismos 
que nos mostram as instâncias da enunciação: procedimentos narrativos, fílmicos e narradores que nos acompanharão ao longo da minissérie.

Na sequência seguinte, vemos os dois meninos na sala de aula e o narrador informa que estamos em uma tarde quente de abril de 1961. Os meninos são expulsos pelo professor por estarem vendo fotografias de mulheres, entre elas Brigitte Bardot. Após a expulsão da sala de aula, aguardam na sala do diretor quando a música "Mr. Sandman", agora tocada no rádio da sala, é interrompida para as notícias e o locutor informa que Yuri Gagarin retornou do espaço em segurança e disse que a terra é azul.

Os dois meninos fogem da escola (e do castigo), mas antes de irem nadar no lago - onde encontrarão o cadáver de Anita -, passam pela igreja onde ocorre uma homenagem ao Senador Marcos Torres, avô do atual prefeito Adriano (Murilo Benício). Em seu discurso, ao lado do industrial da cidade e do delegado, o prefeito lembra a tradição política da família e a importância do avô: amigo de D. Pedro II, dos militares que o sucederam na República e de Getúlio Vargas. Ao longo do discurso o prefeito afirma que "como bom tradicionalista, sempre deu valor à família e às instituições." Sublinha ainda que a cidade deve muito a seu avô senador: a estrada que leva ao Rio de Janeiro, a instalação da indústria de tecidos "gerando renda e emprego" (Figura 2).

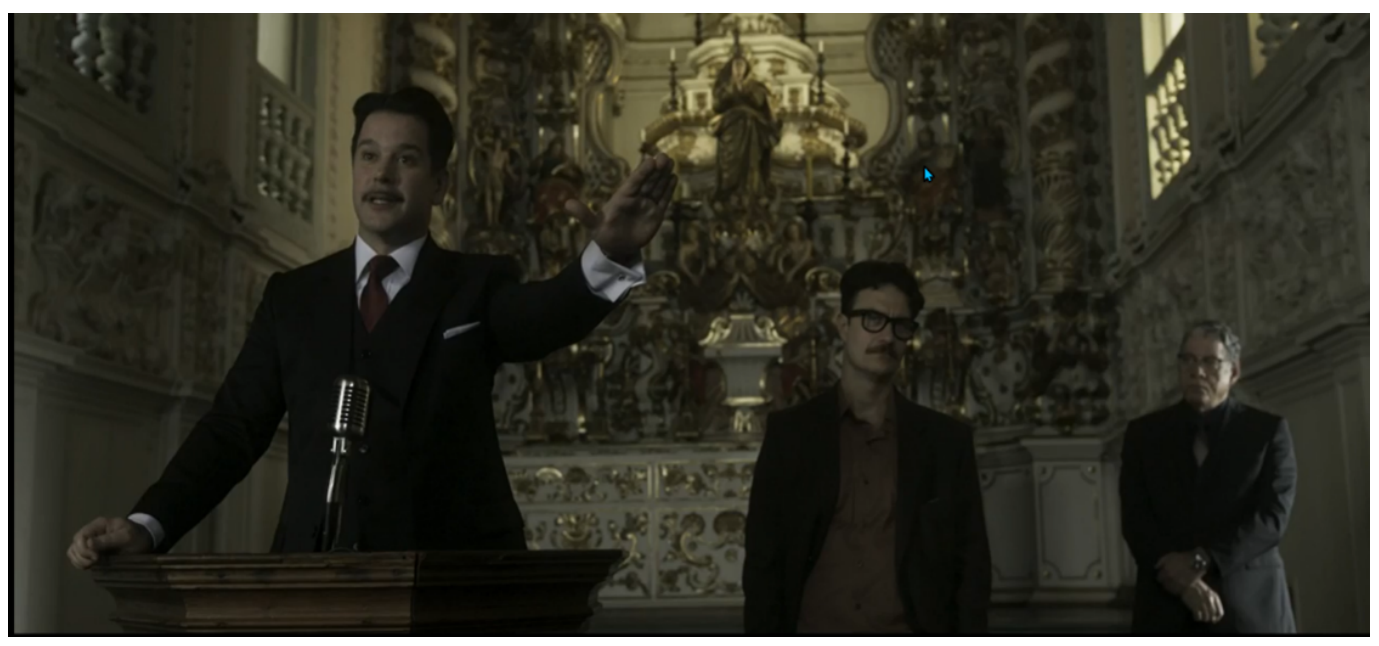

FIGURA 2. Prefeito discursa na igreja ao lado do industrial da cidade e do delegado.

Fonte: Reprodução Globoplay, captura de tela realizada pela autora do artigo 
A realização da homenagem na igreja e a presença no altar do industrial e do delegado mostram as instituições que dão suporte à situação política. O discurso de exaltação ao político do passado destacando sua atuação para a industrialização da cidade nos anos 1950, compõem um cronotopo do Brasil e da política brasileira da época baseado na industrialização, na família e na tradição. O discurso faz convergirem diversas temporalidades que marcam a história do Brasil, comprimindo-as no espaço-tempo da narrativa da minissérie. Nesse sentido, cabe mencionar que Ianni constata as diversas temporalidades e espaços envolvidos na constituição do Brasil moderno:

\footnotetext{
O Brasil Moderno, ao mesmo tempo em que se desenvolve e diversifica, preserva e recria traços e marcas do passado recente e remoto, nesta e naquela região. O país parece um mapa simultaneamente geográfico e histórico, contemporâneo e escravista, republicano, monárquico e colonial, moderno e arqueológico. Toda a sua história está contida no seu presente, como se fosse um país que não abandona nem esquece o pretérito; memorioso (IANNI, 2004, p. 63).
}

Ainda no primeiro capítulo, observamos a construção do cronotopo familiar, ou melhor dizendo da família exemplar. A declaração do prefeito sobre suas filhas e esposa Isabel (Débora Falabella) (10. capítulo, 12'32), também produz efeitos sobre a temporalidade: "Eu tenho a convicção do quanto a mulher faz pela casa. E, graças a Isabel, eu possuo essas duas pérolas: belas, recatadas e do lar" (Figura 3). Os sentidos produzidos pelo enunciado do prefeito, transporta o telespectador para a atualidade e lembra matéria publicada pela revista Veja sobre a esposa do então vice-presidente Michel Temer e que gerou grande repercussão nos meios de comunicação e nas redes sociais em 2016 (LINHARES, 2016).

Novamente, os sentidos ganham mais camadas e remetem a usos e costumes em relação ao discurso sobre a mulher do vice-presidente e sobre as mulheres em geral. O enunciado do político da história ficcional plasma-se ao da revista e aos demais enunciados que circularam nos meios de comunicação. Dessa forma, as camadas de temporalidade do presente diegético misturam-se ao presente do espectador, produzindo sentidos e formas de reconhecimento entre o ficcional e o real. 


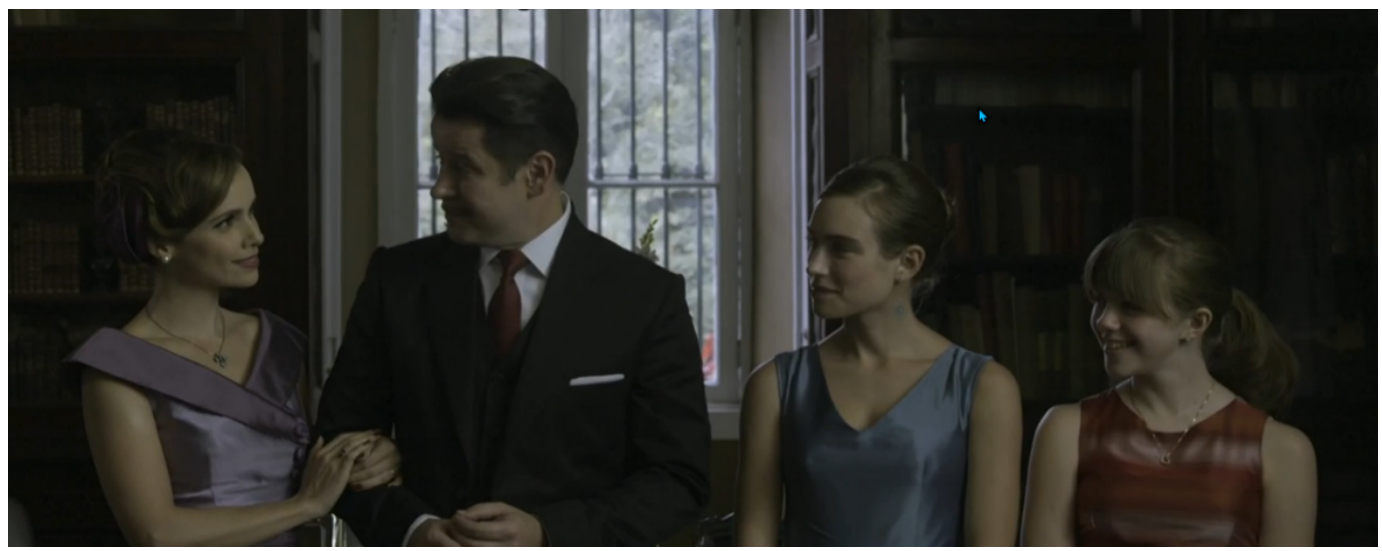

FIGURA 3. Prefeito com sua esposa e as duas filhas: "belas, recatadas e do lar".

Fonte: Reprodução Globoplay, captura de tela realizada pela autora do artigo

Os cronotopos da escola do passado, da amizade entre os meninos, da cidade do interior e o da família tradicional situam-nos no espaço-tempo que predominará ao longo da minissérie. Mas, concomitantemente, situam-nos em um tempoespaço mais amplo caracterizado pela modernidade do avanço tecnológico que permitiu ao homem circundar a terra em uma nave espacial. A chave de leitura introduzida pela romântica música "Mr. Sandman" e pela notícia do feito do astronauta será logo invertida pelo achamento do cadáver de Anita e pela série de assassinatos que se seguirão. O mundo imaginável construído pela trama compõe-se de personagens e conflitos que somente podem ser apreendidos a partir das relações sociais e econômicas que se conjugam por meio da relação tempo e do espaço, ou seja, do cronotopo.

Em termos da construção discursiva da temporalidade, a partir desse momento, a trama, conforme mencionamos anteriormente, contada em primeira pessoa pela voz em off do idoso Paulo Roberto, adquire tom memorialístico e se desenvolve por meio de flashbacks e flashforwards. À maneira de um puzzle, os flashbacks narrativos apresentam-se aos telespectadores não apenas como forma de recompor a motivação do(s) assassino(s) e a dinâmica do crime, mas também como forma de dar força dramática às situações de exploração sexual da jovem assassinada. O recurso estilístico, marcado pela voz testemunhal mostra tanto as relações escusas entre políticos e poderosos de São Miguel, quanto remetem 
a práticas de exploração simbólicas e concretas com relação às mulheres de uma maneira geral e às mulheres pobres de uma maneira mais estrita, corroborando os cronotopos que mencionamos no início de nossa análise.

Outro recurso temporal utilizado no primeiro capítulo são flashforwards que inserem cenas que serão apresentadas nos capítulos posteriores e surgem como elementos que sugerem desdobramentos de conflitos e ações que acontecem com as personagens que interagem no presente diegético. Nesse caso, esse recurso se configura, em termos narratológicos, como uma prolepse narratorial (JOST, 2016, p. 22). Um exemplo desse procedimento pode ser observado na cena (aos 19’56) do primeiro capítulo em que vemos Cecília (Marcela Fetter), a filha do prefeito, aos beijos com Renato (Enzo Romani), um jovem negro jogador do time de futebol da cidade, em um encontro furtivo e, misturados a esse presente diegético vemos flashs de cenas que serão mostradas no segundo capítulo. O jogo entre passado, presente e futuro diegéticos solicita do telespectador atenção constante para que possa se situar entre as diversas temporalidades e encontrar formas de desvendar o mistério que cerca a morte de Anita.

Embora não faça parte do primeiro capítulo, cabe mencionar o uso, no segundo capítulo, de um flashback cuja cena mostrada não corresponde ao discurso da personagem sobre o acontecimento, criando uma espécie de narrador desacreditado que se mostra por meio de um lying flashback (JOST, 2016, p. 21) de modo que a "imagem no interior de um discurso (ou narrativa) coloca em causa a verdade [das imagens]. A visualização pode também desacreditar um discurso verbal que nos colocar sobre uma falsa pista".

Na minissérie em análise, encontramos essa última possibilidade de interpretação, pois a cena a que nos referimos ocorre entre o prefeito Adriano e sua esposa Isabel em um momento em que ele lhe pergunta sobre uma grande quantia de dinheiro encontrada no carro que ele lhe havia emprestado. Tentando explicar a situação embaraçosa, Isabel narra uma história cujos fatos não correspondem às imagens mostradas ao espectador. Esse procedimento permite ao espectador uma posição de cumplicidade em relação à personagem, 
ao mesmo tempo em que aponta os conflitos de confiança existentes entre o poderoso casal de São Miguel.

\section{Considerações}

Ao longo do artigo, analisamos aspectos da construção discursiva da temporalidade na minissérie Se eu fechar os olhos agora, enfatizando sua importância para a composição da trama narrativa. A história, narrada em primeira pessoa pela voz em off de um dos protagonistas, desenvolve-se por meio de flashbacks e flashforwards.

O uso combinado de procedimentos como flashbacks e flashforwards na construção da temporalidade na minissérie caracteriza uma arquitetura de puzzle na qual as peças (personagens, conflitos, motivações) movem-se ao longo do eixo temporal, mesclando passado, presente e futuro na construção do cronotopo como um universo imaginável (TODOROV, 1981, p. 129). Tal arquitetura se configura e se reconfigura partir da enunciação das personagens caracterizada pelo jogo constante de enunciados (verbais e fílmicos) do passado, do presente e do futuro que vão reconstituindo a história ao sabor das descobertas das motivações dos supostos culpados pelo(s) crime(s) calcadas principalmente sobre relações amorosas, extraconjugais e de exploração sexual, que marcam o universo da história. Assim, o universo imaginável ganha corpo por meio das relações tempoespaço como configuradoras de cronotopos por meio dos quais damos sentidos aos enunciados audiovisuais.

O tempo e o espaço tornam-se apreensíveis por meio do acabamento temático e estético que caracterizam os cronotopos analisados ao longo do artigo e que situam as situações e os conflitos para além do espaço da minissérie, mostrando-os a partir de uma perspectiva sócio-histórica. Ao longo da análise, que se deteve no primeiro capítulo da minissérie, observamos cronotopos, que se chocam, ou melhor, se justapõem e mostram suas facetas: a violência contra a mulher, o racismo, o desprezo pela vida humana e pelo uso de práticas políticas que se alinham a um passado marcado pelo coronelismo e pelo clientelismo. 
Características que adentram o mundo da modernidade, representado pelo início da corrida espacial, e nos permitem relacioná-las à noção de destempos discutida por Martín-Barbero (1995, p. 46) e Ianni (2004).

Dessa forma, as diversas temporalidades e seus espaços sociais condensados nos cronotopos mencionados denotam os destempos, ou seja, as diversas temporalidades que não apenas se contrapõem, mas também se superpõem, se justapõem, caracterizadas, por sua vez, pela heterogeneidade que apresenta formações culturais arcaicas, residuais e emergentes lado a lado na sociedade brasileira.

\section{Referências}

BAKHTIN, M. Questões de literatura e estética: a teoria do romance. São Paulo: Hucitec Editora, 2010.

BARONI, R. The many ways of dealing with sequence in contemporary narratology. In: BARONI, R.; REVAZ, F. (orgs.). Narrative sequence in contemporary narratology. Columbus: Ohio State University Press, 2016.

BORDWELL, D. Poetics of cinema. New York: Routledge, 2008.

CLARK, K.; HOLQUIST, M. Mikhail Bakhtin. São Paulo: Perspectiva, 1998.

ECO, U. Lector in fabula. São Paulo: Perspectiva, 1986.

. Seis passeios pelos bosques da ficção. São Paulo: Companhia das Letras, 1997.

ESQUENAZI, J.-P. As séries televisivas. Lisboa: Texto \& Grafia, 2011. 
FORSTER, E. M. Aspectos do romance. São Paulo: Globo, 1998.

GAUDREAULT, A.; JOST, F. Le récit cinématographique: films et séries télévisées. Paris: Armand Colin, 2017.

GENETTE, G. Figuras III. São Paulo: Estação Liberdade, 2017.

IANNI, O. A idéia de Brasil moderno. São Paulo: Brasiliense, 2004.

JOST, F. De quoi les séries américaines sont-elles le symptôme. Paris: CNRS Éditions, 2011.

- Repenser le futur avec les séries. Essai de narratologie comparé. Television, numéro 7. Paris: CNRS, 2016.

KUHN, A.; WESTWELL, G. Oxford Dictionary of Film Studies. Oxford: Oxford University Press, 2012.

LINHARES, J. Marcela Temer: bela, recatada e "do lar". Revista Veja, 18 de abr. 2016. Disponível em: https://veja.abril.com.br/brasil/marcela-temer-bela-recatada-e-do-lar/. Acesso em: 15 out. 2020.

MARTÍN-BARBERO, J. Dos meios às mediações: comunicação, cultura e hegemonia. Rio de Janeiro: Editora da UFRJ, 2001.

América Latina e os anos recentes: o estudo da recepção em comunicação social. In: SOUSA, M. W. (org.). Sujeito: o lado oculto do receptor. São Paulo: Brasiliense, 1995.

METZ, C. A significação no cinema. São Paulo: Perspectiva, 2010. 
MITTELL, J. Narrative Complexity in Contemporary American Television. The velvet light trap. Number 58, University of Texas Press, 2006.

MITELL, J. Complex TV: the poetics of contemporary television storytelling. New York: New York University Press, 2015.

MUNGIOLI, M. C. P. Poética das Séries de Televisão: elementos para conceituação e análise. Anais. Congresso Brasileiro de Ciências da Comunicação, 2017. Disponível em: http://portalintercom.org.br/anais/nacional2017/resumos/R12-2621-1.pdf. Último acesso em: 13 out. 2017.

MUNGIOLI, M. C. P. A dupla articulação gênero-formato ficcional como instância de mediação local. In: TRINDADE, E.; LACERDA, J. S.; FERNANDES, M. (orgs.). Entre comunicação e mediações: visões teóricas e empíricas. São Paulo: ECA-USP, 2019; Paraíba: UEPB, 2019.

MUNGIOLI, M. C. P. Entre o ético e o estético: o carnavalesco e o cronotopo na construção do narrador da minissérie Capitu. Revista Líbero, v. 16, n. 31, jan.-jun. de 2013.

MUNGIOLI, M. C. P.; PELEGRINI, C. Narrativas complexas na ficção televisiva. Revista Contracampo, v. 26, 2013.

PALLOTTINI, R. Dramaturgia de televisão. São Paulo: Moderna, 1998.

RICOEUR, P. Temps et récit. Tome I: L'intrigue et le récit historique. Paris: Éditions du Seuil, 1983.

RYAN, M.L. Paradoxes temporels dans le récit. A contrario, v. 13, n. 1, 2010. 
SILVA, M. V. B. Cultura das séries: forma, contexto e consumo de ficção seriada na contemporaneidade. Revista Galáxia, n. 27, 2014. Disponível em: http://dx.doi.org/10.1590/1982-25542014115810. Acesso em: 10 jul. 2017.

SEPULCHRE, S. Décoder les séries télévisées. Bruxelas: Éditions De Boeck Université, 2011.

TODOROV, T. Mikhail Bakhtine: le principe dialogique suivi de écrits du cercle de Bakhtine. Paris: Seuil, 1981.

TOMACHEVSKI, B. Temática. In: Toledo, D. O. (org.) Teoria da literatura: formalistas russos. Porto Alegre: Globo, 1976.

WILLIAMS, R. Televisão: tecnologia e forma cultural. São Paulo: Boitempo; Belo Horizonte: PUC Minas, 2016.

Submetido em: 21 out. 20 | aprovado em: 22 nov. 20 